\title{
Pneumococcal Immunisation Coverage Among Infants Between 4-12 Months in Nyamira County, Kenya
}

\author{
Jane Karicha $^{1^{*}} \quad$ Justus Osero $^{1} \quad$ Stanley Kimuhu ${ }^{2}$ \\ 1.Department of Community Health \& Epidemiology, Kenyatta University \\ 2.Department of Pediatrics \& Child Health
}

\begin{abstract}
Background: Pneumonia is the leading killer among all infectious diseases worldwide. Though treatable, it often results in high mortality and morbidity therefore putting pressure on available health resources. The best intervention for pneumonia is prevention through vaccination.

Objective. To determine pneumococcal vaccine coverage among infants between 4-12 months in Nyamira County Methods: A cross sectional design was used in this study. Using questionnaires. Caregivers were interviewed and a checklist was used to review the vaccination records. Data was analyzed using descriptive statistics and inferential statistics.

Results: The results indicated that coverage of $82.5 \%$ for PCV 10 vaccine is below the recommended $90 \%$. Caregivers were predominantly female, $97 \%$ and in informal employment. Among the demographic factors of the cohort, level of education was found to be statistically significant with $p$ values of 0.029 as calculated using Fischer's Exact. Care Givers were asked whether they had other children that were below 5 years so as to determine whether their previous experience with their children made any impact on the vaccine coverage. This demographic factor was also found to be significant with a $\mathrm{P}$ value of 0.019 as calculated using Chi Square. and the number of other children Caregivers had (besides the infant being studied) that were below 5 years were found to and respectively.

Conclusion and Recommendations: Coverage of pneumococcal vaccine in Borabu Sub-County, Nyamira County was $(82.5 \%)$, still below the internationally recommended target of $90 \%$. Uptake of PCV 10 vaccine was found to be influenced by Knowledge about the PCV 10 vaccine, level of education of Caregivers and the age of children that Caregivers had who were below 5 years. The coverage of PCV 10 vaccine in Borabu Sub County in Nyamira County can be enhanced by increasing knowledge of Caregivers on PCV 10 vaccine and by increasing compliance to the vaccination schedule. This can be done through various channels such as use of mobile phonebased reminders and community sensitization campaigns. A study can be done to identify effective interventions for delivering health education about pneumococcal vaccine in rural populations. In addition, interventional studies may be done to test effectiveness of reminder systems on immunization uptake.
\end{abstract}

Keywords: uptake, coverage, PCV 10, pneumococcal vaccine.

DOI: $10.7176 / \mathrm{JNSR} / 11-22-01$

Publication date: November $30^{\text {th }} 2020$

\section{Background}

Pneumonia is a lower respiratory tract infection that affects one or both lungs and is one of the leading causes of death in children below 5 years worldwide and a leading killer among all infectious diseases. It is most prevalent in South Asia and sub-Saharan Africa (WHO, 2016). It can be prevented through immunization, proper nutrition and management of environmental factors. While the bacterial infection can be treated with antibiotics, only a third of the children who get sick are able to access the antibiotics due to various reasons including cost. Bacterial Pneumonia is caused by Streptococcus pneumonia and may result in invasive pneumococcal diseases (IPD) such as bacteraemia, meningitis and bacteremic pneumonia, or in non-IPD, such as pneumonia, sinusitis and Otitis media (McClure, Ford, \& Wilson, 2006). Children younger than 5 years are at highest risk of both IPD and nonIPD. Preventive measures must therefore be provided at the earliest age possible because the vulnerability is highest at the young age.

One of the vaccines that are available against pneumonia is PCV-10 vaccine; a ten-valent vaccine that targets 10 strains of S. pneumonia that cause IPD; this form of pneumonia is the most fatal. The vaccine has demonstrated $100 \%$ Efficacy against IPD (Tregnaghi et al., 2014).

Compared with the other vaccines available for childhood vaccination, PCV is one of the vaccines whose coverage remains low. By 2017, PCV had been introduced to 135 countries and the global coverage was estimated at $44 \%$ compared with DPT at $90 \%$ in 123 countries, (WHO, 2018). Sub-Saharan Africa is one of the regions where the coverage of PCV remains low achieving coverage less than $60 \%$ as indicated by (WHO, SAGE, 2017). The recommended routine vaccination of PCV is either three doses with DPT or 2 doses before 6 months of age, plus booster dose at 9-15 months of age, (WHO, 2018). Kenya has adopted the former routine.

Immunization coverage is critical as a determinant of the number of children that can be saved from the infections. Since introduction, 190,000 deaths have been averted, (WHO, 2017); the more reason why uptake of 
PCV 10 vaccine in Kenya is critical. In Kenya, six per 1000 deaths in under five were caused by pneumonia contributing to $15 \%$ of all child deaths in 2018, (Mugo, 2020). Pneumonia was identified as the leading killer disease in 2012 ahead of malaria with 19,011 cases, accounting for 10.9\% deaths (Kenya National Bureau of Statistics, 2013). In addition, "Statistics from the Ministry of Public Health and Sanitation indicate that one in every five deaths in the country is attributed to pneumonia" (University of Nairobi, 2013).

In 2013, Nyamira County's leading cause of death was pneumonia different from the national, which was HIV/AIDs, (Department of Health Services, 2014). In addition, under five leading cause of death was reported as pneumonia (KNBS, 2015) making this an important county of study. In 2018, while the national under five mortalities due to pneumonia was six per 1000, Nyamira was among the 12 counties with more than double the rate: 12-14 deaths per 1000, (Mugo, 2020). Despite the availability of the vaccine (PCV 10) for prevention of the disease, the uptake has continued to decline in the county compared with national. The national Full Immunization Coverage (FIC) for children below one year decreased by 3\% between 2016 and 2017 in Kenya while in Nyamira County it decreased by $23 \%$ between the same period, (Kenya National Bureau of Statistics, 2018). Similarly, the coverage of PCV 10 was even lower in Borabu Sub County compared to the County. In 2017, the PCV 10 coverage in the County was $64 \%$ while Borabu Sub County was $61 \%$ for the third dose, (County Government of Nyamira, 2018). In Borabu Sub-County, coverage of PCV 10 decreased from 83\% in 2013 to 61\% in 2017 (County Government of Nyamira, 2018).

In Kenya, an efficacy study in Kilifi established that PCV 10 results in an estimated $42.7 \%$ reduction in pneumococcal disease episodes and a $6.1 \%$ reduction in childhood deaths, (WHO, 2015). PCV 10 reduces pneumococcal bacterium in the population by two thirds therefore offering not just individual protection but also herd immunity (Hammitt, 2014). It is therefore a key pillar in reduction of pneumonia infections and deaths. On the other hand, S. pneumonia, one of the causes of pneumonia has shown resistance to antibiotics used in treatment. Reducing the number of infections will help preserve the antibiotics. In Kenya, few studies exist in the country that could inform the intervention on PCV 10 vaccine uptake.

\section{Methods and Materials.}

Study Area, Period and Design

The study location was Borabu Sub-county in Nyamira County. A cross sectional study design was applied to assess the PCV vaccination uptake among Caregivers between February 1st and February 27th 2020.

\section{Study Population}

Caregivers of children between the ages of 4 to 12 months.

\section{Sample size and sample size determination}

The Statistical Cochran equation was applied to determine sample: size $\mathrm{n}_{0}=\mathrm{Z} 2 \mathrm{pq} / \mathrm{e} 2 \mathrm{Where}$; $0=$ sample size, $\mathrm{Z}$ is the abscissa of the normal curve that cuts off an area $\alpha$ at the tails; at the desired confidence level of $95 \% Z=1.96$; $p$ is the estimated proportion of an attribute that is present in the population; $p=0.67$ (percentage of infants between 4-12 months that are likely to be immunized based on administrative immunization coverage for 2017 at $67 \%$ ), (County Government of Nyamira, 2018).

\section{Sampling Technique}

Nyamira County and Borabu Sub County were purposively selected for this study due to the low PCV 10 immunization coverage (County Government of Nyamira, 2018). Simple random sampling was used for the wards, the Community Health Units (CHU) and the households within the Sub County. Community Health Extension Workers (CHeWs) assigned to the respective units helped in random sampling of the households within each community unit for Caregivers of 4-12 months' infants. For households with more than one Caregiver of 4-12 months' infant, simple random sampling was applied.

\section{Eligibility Criteria}

\section{- Inclusion criteria}

All resident Caregivers of infants between 4 to 12 months that were in Borabu sub county between February 1 st and February 27th 2020 of June 1 to June 30, 2018.

\section{- Exclusion Criteria}

Caregivers of infants between 4 to 12 months that had visited the Sub County and those that did not consent to the study and were excluded.

\section{Data collection instrument}

The data was collected by use of interviewer-administered questionnaires. The research assistants were taken through basic training on interviewing techniques to enhance validity of the data collected. A checklist was used 
to obtain objective data on the child's immunisation status.

\section{Data Quality Assurance}

Before actual implementation of the study, a pre-test of the questionnaires was done on a sample of households selected randomly from Bosamaro ward in Nyamira South Sub County, Nyamira County to ensure that the questionnaire produced similar results on repeated interviews. Any questions that were generating varied responses on repeated administration were revised to enhance consistency. The questionnaires were subjected to reviews by experts in child health to ascertain the content validity of the questions in assessing immunization status of the eligible infants and knowledge of caregivers about the vaccine. Data collected was first checked for completeness and accuracy then analysis was conducted using descriptive and inferential statistics.

\section{Ethical Considerations}

The study attained approvals from the relevant bodies including, Kenyatta University Ethical Review Committee and the National Commission for Science and Technology (NACOSTI). Permission to collect data was also sought from the county administrative offices before commencement of fieldwork. Privacy and confidentiality of the information from the respondents was ensured by having all interviews done in private. Before participation in the study, all respondents signed an informed consent form after being informed of the purpose and their expected roles in the study. The questionnaires were anonymous.

\section{Results}

The sample predominantly comprised of females $(96.8 \%, \mathrm{n}=349)$ and only $3.2 \%$ were male (Table 1.1$)$. The median age of children between 4 to 12 months was 9 months. Most caregivers had some form of education. The number of caregivers with secondary level of education was the highest at $57.9 \%$ followed by primary at $32.1 \%$ while the university level had the least population at $2 \%$, (Table 1.1). Most caregivers were in informal employment (90.49\%) and only 6.05\% were formally employed, (Table 1.1). The level of education of caregivers was found to be significant in terms of association with the vaccine uptake; $(\mathrm{P}=0.029)$ (Table 1.2).

Table 1.1: Socio-demographic characteristics of the Caregivers

\begin{tabular}{|c|c|c|}
\hline Characteristic & Frequency & $\%$ \\
\hline \multicolumn{3}{|c|}{$\operatorname{Sex}(n=348)$} \\
\hline Men & 11 & 3.2 \\
\hline Female & 337 & 96.9 \\
\hline \multicolumn{3}{|c|}{ Education $(n=349)$} \\
\hline None & 1 & 0.39 \\
\hline Primary & 112 & 32.1 \\
\hline Secondary & 202 & 57.9 \\
\hline College & 27 & 7.7 \\
\hline University & 7 & 2 \\
\hline \multicolumn{3}{|c|}{ Occupation $(n=347)$} \\
\hline Unemployed & 12 & 3.46 \\
\hline Informally employed & 314 & 90.49 \\
\hline Formally employed & 21 & 6.05 \\
\hline \multicolumn{3}{|c|}{ Number of other children the Caregiver had that were below 5 years $(n=351)$} \\
\hline $1-3$ & 334 & 95.16 \\
\hline$>3$ & 17 & 4.84 \\
\hline
\end{tabular}

Similarly, the number of other children that the Caregivers had that were below 5 years was also significantly associated with the vaccine uptake $\left(\chi^{2}=29 ; \mathrm{df}=1 ; \mathrm{p}=0.019\right)$ (Table 1.2). a higher percentage (95.16) of Care Givers that had other children between 1 and 3 years (besides the infant being studied) vaccinated their children. This compares to only $4.84 \%$ of the Care Givers with children $>3$ years but below 5 years (besides the infant being studied). The age and occupation of the caregivers were not statistically significant in terms of association with the vaccine uptake with $\mathrm{p}$ values of 0.28 and 0.30 respectively, (Table 1.2). the age of the Caregiver and their occupation did not determine whether they took the infants for vaccination or not. 
Table 1.2: Bivariate analysis of association of socio-demographic factors to vaccine uptake

\begin{tabular}{|c|c|c|c|c|c|}
\hline \multirow[t]{2}{*}{ Variable } & \multicolumn{2}{|c|}{$\begin{array}{l}\text { Pneumococcal vaccination } \\
\text { uptake }\end{array}$} & & \multirow[t]{2}{*}{ Test } & \multirow[t]{2}{*}{$\begin{array}{l}\text { Test } \\
\text { Significance }\end{array}$} \\
\hline & $\begin{array}{l}\text { Not fully } \\
\text { vaccinated }(\%)\end{array}$ & $\begin{array}{l}\text { Fully } \\
\text { vaccinated } \\
(\%)\end{array}$ & Totals & & \\
\hline \multicolumn{6}{|l|}{ Level of education } \\
\hline None & $1(100)$ & $0(0)$ & $1(100)$ & \multirow{5}{*}{$\begin{array}{l}\text { Fisher's } \\
\text { exact }\end{array}$} & \multirow[t]{5}{*}{$0.029^{*}$} \\
\hline Primary & $27(24.11)$ & $85(75.89)$ & $112(100)$ & & \\
\hline Secondary & $31(15.35)$ & $171(84.65)$ & $202(100)$ & & \\
\hline College & $2(7.41)$ & $25(92.59)$ & $27(100)$ & & \\
\hline University & $0(0)$ & $7(100)$ & $7(100)$ & & \\
\hline Age of caregivers & $\begin{array}{l}\text { Mean age: } 27.9 \\
\text { years }\end{array}$ & $\begin{array}{l}\text { Mean age: } \\
27.1 \text { years }\end{array}$ & & t-test & 0.31 \\
\hline \multicolumn{6}{|l|}{ Occupation } \\
\hline Unemployed & $0(0)$ & $12(100)$ & $12(100)$ & \multirow{3}{*}{$\begin{array}{l}\text { Fisher's } \\
\text { exact }\end{array}$} & \multirow[t]{3}{*}{0.28} \\
\hline Informally employed & $58(18.47)$ & $256(81.53)$ & $314(100)$ & & \\
\hline Formally employed & $3(14.29)$ & $18(85.71)$ & $21(100)$ & & \\
\hline $\begin{array}{l}\text { Number of other children } \\
\text { below } 5 \text { years }\end{array}$ & & & & \multirow{3}{*}{$\begin{array}{l}\text { Chi square, } \\
X^{2}=29 \\
d f=1\end{array}$} & \multirow[t]{3}{*}{$0.019 *$} \\
\hline $1-3$ & $55(16.47)$ & $279(83.53)$ & $334(100)$ & & \\
\hline$>3$ & $6(40.00)$ & $9(60.00)$ & $15(100)$ & & \\
\hline
\end{tabular}

Coverage of pneumococcal vaccine among infants between 4 to 12 months

The objective of this study was to determine pneumococcal immunization coverage of infants between 4 to 12 months. Data on the vaccination uptake was obtained by first asking the caregivers whether their children had been vaccinated, and then going further to verify the details from child's immunization card. The overall uptake of pneumococcal vaccine was dichotomized into fully vaccinated (all three doses given) and not fully vaccinated (less than three doses).

A breakdown of the number of pneumococcal vaccine doses received and the overall vaccine uptake is presented in table 1.3 . Overall, a majority $(82.5 \%$,) of the infants had been fully vaccinated for PCV 10 while $17.48 \%$ were not fully vaccinated, (Table 1.3$)$. Of the children that were not fully vaccinated $(6 \%)$ had received none of the three vaccine doses that are recommended, $4.3 \%$ had received only one dose and $6.88 \%$ had received two doses (Table 1.3). Among the infants who had been partially vaccinated, (62\%) of them received only two doses while $38 \%$ received only one dose among the not fully immunized children (Figure 1.2).

Table 1.3: Pneumococcal vaccine uptake

\begin{tabular}{|l|l|}
\hline Variable & Frequency \\
\hline None & Number of PCV vaccine doses received $(\mathbf{n}=\mathbf{3 4 9})$ \\
\hline One dose & $22(6.3 \%)$ \\
\hline Two doses & $15(4.3 \%)$ \\
\hline Three doses & $24(6.88 \%)$ \\
\hline \multicolumn{2}{|c|}{ PCV uptake $\mathbf{n}=(\mathbf{3 4 9})$} \\
\hline Not fully vaccinated & $61(17.48 \%)$ \\
\hline Fully vaccinated & $288(82.52 \%)$ \\
\hline
\end{tabular}


Figure 1.1: Proportion of doses given to children not fully vaccinated.

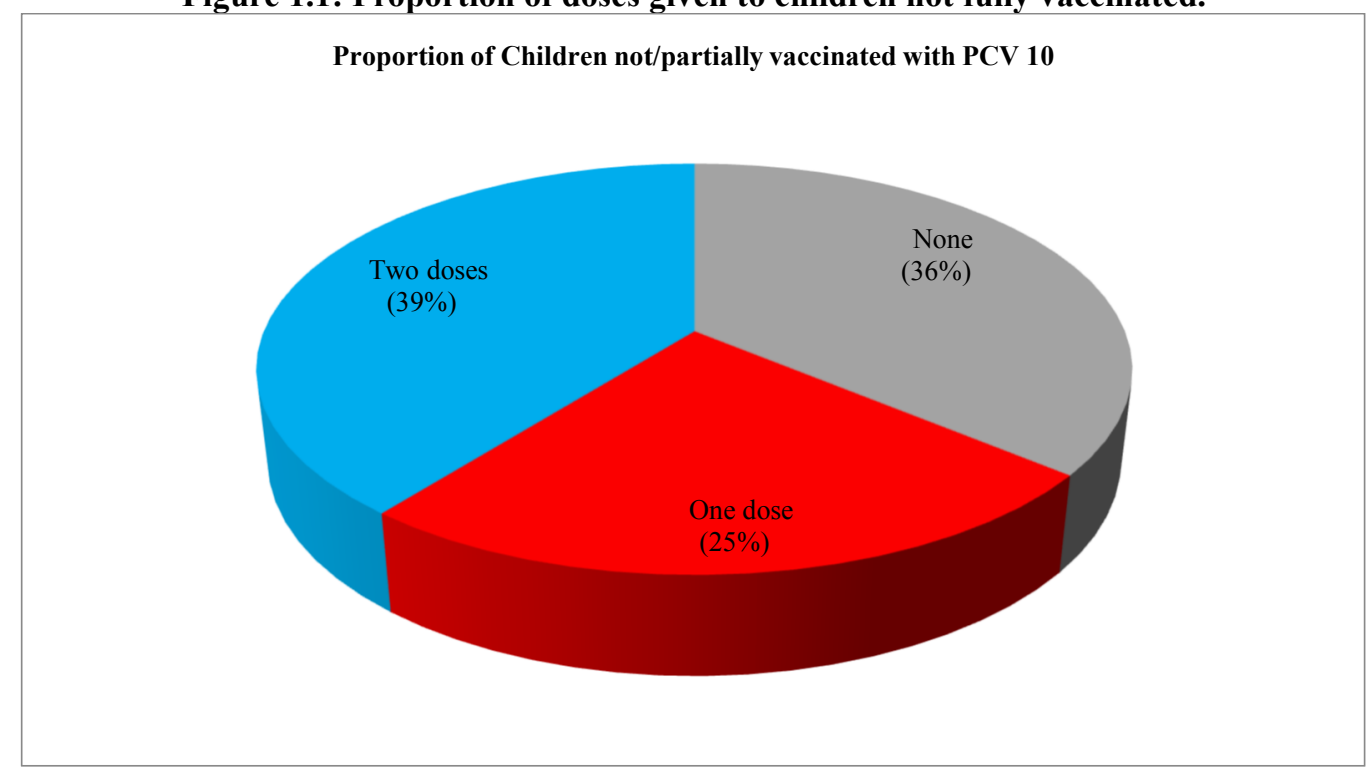

Figure 1.2: Partially vaccinated children

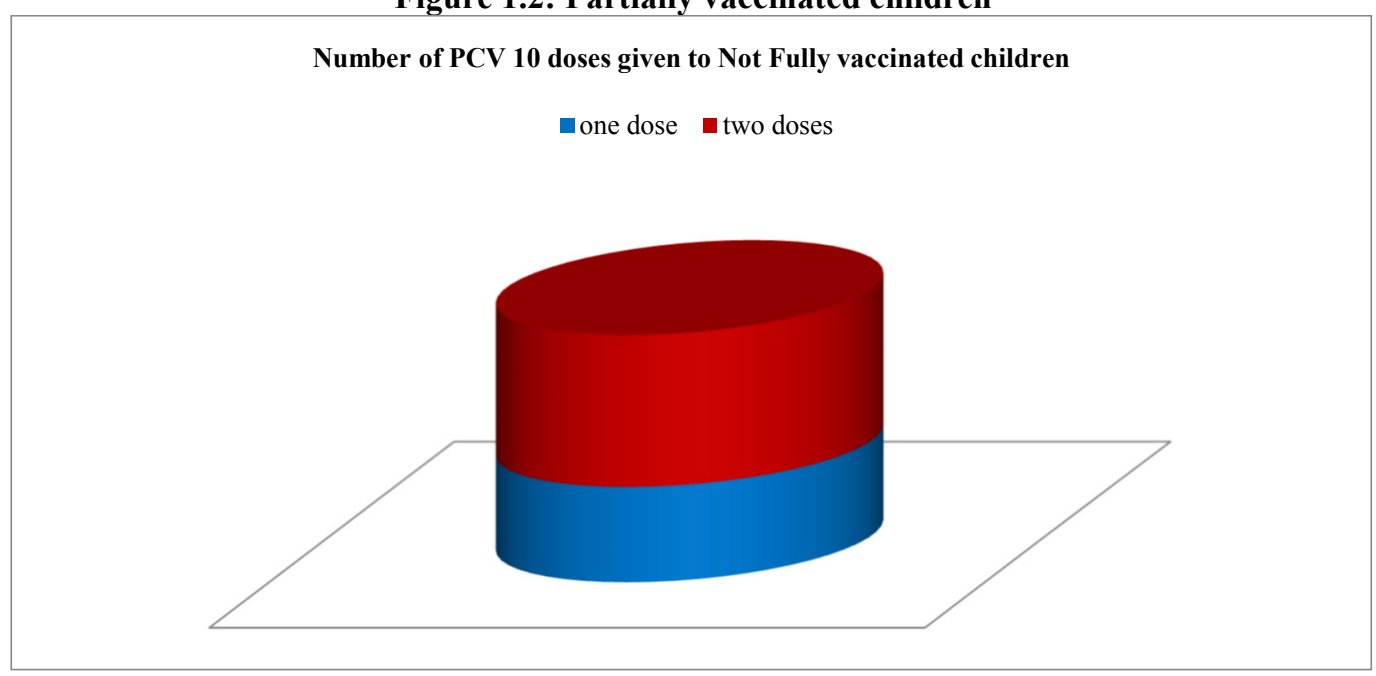

\section{Conclusion and Recommendations}

Coverage of pneumococcal vaccine in Borabu Sub-County, Nyamira County was (82.5\%), still below the internationally recommended target of $90 \%$. Based on the findings from this study it is recommended that in order to increase vaccine coverage, adherence to the vaccination schedule should be enhanced with reminders and increased capacities of lower level health facilities. The Health system should consider mass sensitization campaigns to increase awareness and knowledge about the PCV 10 vaccine in Nyamira County. This study presents opportunity for further research one of which would be to identify effective interventions for delivering health education about pneumococcal vaccine in rural populations. Interventional studies may also be done to test effectiveness of reminder systems on immunization uptake.

\section{References}

County Government of Nyamira. (2018). Immunization Performance for Year 2013 to 2017. Nairobi: County Government of Nyamira.

Department of Health Services. (2014). County Health Strategic \& Investment Plan 2013/14-2017/18. Nairobi: County Government of Nyamira.

Israel, G. (2009). Determining Sample Size. Retrieved January 30, 2018, from www.psycholosphere.com: http://sociology.soc.uoc.gr/socmedia/papageo/metaptyxiakoi/sample_size/samplesize1.pdf

National Bureau of Statistics. (2013). Economic Survey 2013. Nairobi: Kenya National Bureau of Statistics.

KNBS. (2015). County Statistical Abstract, Nyamira County. Nairobi: KNBS. 
Laura L Hammitt, D. O. (2014, July). Pneumococcal vaccination of children in Kenya can provide 'herd protection' to unvaccinated population. The Lancet, Global Health, pp. e397-e405. Retrieved June 14, 2018, from http://kemri-wellcome.org: http://kemri-wellcome.org/news/pneumococcal-vaccination-of-children-inkenya-can-provide-herd-protection-to-unvaccinated-population/

Leung, K. C., Mui, C., Chiu, W. Y., Ng, Y. Y., Chen, M. H. Y., Ho, P. H., . . Pang, H. H. (2017). Impact of patient education on influenza vaccine uptake among community-dwelling elderly: a randomized controlled trial. Health Education Research, 32(5), 455-464. doi: 10.1093/her/cyx053

McClure, C. A., Ford, M. W., \& Wilson, J. B. (2006, January). Pneumococcal conjugate vaccination in Canadian infants and children younger than five years of age: Recommendations and expected benefits. Canadian Journal of Infectious Diseases and Medical Microbiology, 19-26. Retrieved January 25, 2018, from NCBI: https://www.ncbi.nlm.nih.gov/pmc/articles/PMC2095050/

Ministry of Health, K. (2013). Kenya Health Sector Strategic and Investment Plan (KHSSPI) July 2013-June 2017.

Mugo, D. (2020, JANUARY 13). Pneumonia scourge: Poverty a leading cause of deaths among children. Daily Nation.

Olayinka, F., Ewald, L., \& Steinglass, R. (2017). Beyond new vaccine introduction: the uptake of pneumococcal conjugate vaccine in the African Regio. The Pan African Medical Journal.

Pollard, A. J. (2007). Childhood immunisation: what is the future? Archives of Disease in Childhood, 426-433.

Orji, R., Vassileva, J., \& Mandryk, R. (2012). Towards an effective health interventions design: an extension of the health belief model. Online journal of public health informatics, 4(3), ojphi.v4i3.4321. doi: 10.5210/ojphi.v4i3.4321

Tregnaghi, M. W., Sáez-Llorens, X., López, ,. P., Abate, H., Smith, E., Adriana, P., . . Lode, S. (2014, June 3). Efficacy of Pneumococcal Nontypable Haemophilus influenzae Protein D Conjugate Vaccine (PHiD-CV) in Young Latin American Children: A Double-Blind Randomized Controlled Trial. Retrieved January 26, 2018, from PLOS Medicine: http://journals.plos.org/plosmedicine/article?id=10.1371/journal.pmed.1001657

UNICEF. (2019, NOVEMBER). PNEUMONIA. Retrieved APRIL 28, 2020, from www.unicef.org: https://data.unicef.org/topic/child-health/pneumonia/

UNICEF/WHO. (2013). Ending Preventable Child Deaths from Pneumonia and Diarrhoea by 2025: The integrated Global Action Planfor Pneumonia and Diarrhoea (GAPPD). GENEVA: WHO.

University of Nairobi. (2013, May 24). Pneumonia biggest killer disease in Kenya . Retrieved January 23, 2018, from University Health Services: http://healthservices.uonbi.ac.ke/node/810

WHO. (2015, April). Immunization: Closing the gap on pneumonia in Kenya. Retrieved from www.who.int: https://www.who.int/features/2015/kenya-closing-pneumonia-gap/en/

WHO. (2016, 11 7). Pneumonia. Retrieved from World Health Organisation: https://www.who.int/newsroom/fact-sheets/detail/pneumonia

WHO. (2017). Closing the immunization gap. Geneva: WHO.

WHO. (2017). Pneumococcal Conjugate Vaccine (PCV) Review of Impact Evidence (PRIME). Washington: WHO.

WHO. (2017, 11 4). SAGE evidence to recommendations table. Retrieved from www.who.int: https://www.who.int/immunization/sage/meetings/2017/october/4_PCV_WG_MERGED_Evidence_to_Rec SEPT 26.pdf

WHO. (2018, 7 16). Immunization coverage. Retrieved APRIL 25, 2020, from www.who.int: https://www.who.int/news-room/fact-sheets/detail/immunization-coverage

WHO. (2018, 12). Summary of WHO Position Papers - Recommendations for Routine Immunization. Retrieved from www.who.int: https://www.who.int/immunization/policy/Immunization_routine_table1.pdf?ua=1

WHO. (2019, December 6). Immunization coverage. Retrieved APRIL 25, 2020, from www.who.int: https://www.who.int/en/news-room/fact-sheets/detail/immunization-coverage

WHO, SAGE. (2017). SAGE, October 2017. Geneva: Who. 